\title{
GOUT AND THE RISK OF PARKINSON'S DISEASE IN DENMARK
}

\author{
Eva Schernhammer ${ }^{1,2,3}$, Jiaheng Qiu ${ }^{4}$, Lene Wermuth ${ }^{5}$, Christina Funk Lassen ${ }^{6}$, Soren \\ Friis $^{6}$, and Beate Ritz ${ }^{4}$ \\ ${ }^{1}$ Channing Division of Network Medicine, Department of Medicine, Harvard Medical School, \\ Boston, MA 02115, USA \\ ${ }^{2}$ Department of Epidemiology, Harvard School of Public Health, Boston, MA 02115, USA \\ ${ }^{3}$ LBI-ACR \& ACR-ITR VIEnna/CEADDP, Vienna, Austria \\ ${ }^{4}$ Department of Epidemiology, UCLA School of Public Health, Los Angeles, CA 90095, USA \\ ${ }^{5}$ Department of Neurology, Odense University Hospital, Odense, Denmark \\ ${ }^{6}$ Danish Cancer Society Research Center, Danish Cancer Society, Copenhagen, Denmark
}

\section{Keywords}

gout; parkinson

\begin{abstract}
There is growing evidence that oxidative stress plays a major role in Parkinson's Disease (PD) etiology [1,2]. Importantly, uric acid has been shown in experimental studies to have an antioxidant effect on neurons [3,4]. Recently, several observational studies have also evaluated associations between serum uric acid levels and PD risk and have consistently reported a lower risk of PD among individuals with the highest levels of serum uric acid [510]. The most common metabolic disorder underlying hyper-uricemia is gout. Thus, if hyperuricemia decreases the risk of PD, gout should also be negatively associated with PD risk. Two studies, to date, have evaluated the association between gout and PD risk and both reported an inverse association $[11,12]$, although the association was only observed among men in one of the two studies [11].

Using Danish population registers, we aimed to confirm the findings from these two previous observational studies. We investigated whether a history of use of anti-gout prescription medications was associated with PD risk. From nationwide Danish in- and outpatient Hospital Register records, we identified 4,484 patients with a first time diagnosis of PD between 2001-2008 and a diagnosis confirming PD medication history according to the Danish National Prescription Registry (DNPR) that records all prescription in Denmark since 1995 [13]. We randomly selected 22,416 population controls from the Danish Civil Registration System [14], density-matched by birth year and sex. We extracted information about the use of anti-gout drugs from the DNPR for all study participants. Exposure was defined as at least one prescription of anti-gout drugs prior to the first diagnosis of PD for the cases or the corresponding date (index date) for their matched controls. Prescriptions included Anatomical Therapeutic Chemical (ATC) group M04 anti-gout preparations
\end{abstract}

Correspondence to: Eva S. Schernhammer, MD, DrPH, Channing Laboratory, 181 Longwood Avenue, Boston, MA 02115. Tel: (617) 525-4648; Fax: (617) 525-2008; eva.schernhammer@ channing.harvard.edu.

AUTHOR ROLES:

Research project conception (ES, LW, SF, BR); statistical analyses design (ES, BR) and execution (JQ); manuscript writing and review (ES, JQ, LW, CFL, SF, BR). 
(M04AA preparations inhibiting uric acid production (e.g., allopurinol), M04AB preparations increasing uric acid excretion (e.g., benzbromarone), M04AC preparations with no effect on uric acid metabolism (e.g., colchicine), and M04AX (other anti-gout preparations, e.g., urate oxidase). Odds ratios (OR) were estimated using logistic regression models adjusted for age, sex, and chronic obstructive pulmonary disease as an indicator of smoking. Further details of the study and methods, including baseline characteristics of the study population, have been provided elsewhere [15].

We found no associations between the use of anti-gout medications and risk of PD. This lack of an association did not differ by gender or age at onset of PD (Table 1). Results were similar when we excluded PD cases that occurred within 2 or 5 years after first use of antigout drugs. Similarly, adjustment for use of diuretic medications or of non-steroidal antiinflammatory drugs did not alter our findings.

Limitations of our study include the potential for exposure misclassification, which may have biased our results towards the null, and that we were unable to control for possible confounders such as smoking habits and caffeine intake; however, we did adjusted for COPD as a surrogate for heavy smoking. Main strength of our study is that it included four times the number of PD patients compared to the previous studies.

In sum, data from this large case-control study did not provide support for an inverse association between anti-gout medication intake in the decade before PD onset and risk of PD. This suggests that uric acid levels in those using anti-gout medications may not have been high enough to protect from PD or that it is not adequate to use gout treatment prescription records as indicators of high uric acid levels, even though both previous epidemiologic studies used similar record systems and reported that the PD risk reduction was strongest among treated gout patients. Our data also preserve the possibility that there may not be an important effect of hyperuricaemia on PD in humans.

\section{Acknowledgments}

This study was supported by a grant from the National Institutes of Environmental Health Sciences, USA (grant No R01 ES013717). Partial funding was also provided by the National Institutes of Neurologic Diseases and Stroke, USA for the UCLA Udall Parkinson Disease Center of Excellence grant No P50 NS038367). The funding source had no role in the design or analysis of the study or in the decision to submit the manuscript for publication.

\section{References}

1. Jomova K, Vondrakova D, Lawson M, Valko M. Metals, oxidative stress and neurodegenerative disorders. Mol Cell Biochem. 2010; 345(1-2):91-104. [PubMed: 20730621]

2. Kyrozis A, Ghika A, Stathopoulos P, Vassilopoulos D, Trichopoulos D, Trichopoulou A. Dietary and lifestyle variables in relation to incidence of Parkinson's disease in Greece. European journal of epidemiology. 2013

3. Church WH, Ward VL. Uric acid is reduced in the substantia nigra in Parkinson's disease: effect on dopamine oxidation. Brain Res Bull. 1994; 33(4):419-25. [PubMed: 8124580]

4. Tohgi H, Abe T, Takahashi S, Kikuchi T. The urate and xanthine concentrations in the cerebrospinal fluid in patients with vascular dementia of the Binswanger type, Alzheimer type dementia, and Parkinson's disease. J Neural Transm Park Dis Dement Sect. 1993; 6(2):119-26. [PubMed: 8117408]

5. Davis JW, Grandinetti A, Waslien CI, Ross GW, White LR, Morens DM. Observations on serum uric acid levels and the risk of idiopathic Parkinson's disease. Am J Epidemiol. 1996; 144(5):480-4. [PubMed: 8781463]

6. de Lau LM, Koudstaal PJ, Hofman A, Breteler MM. Serum uric acid levels and the risk of Parkinson disease. Ann Neurol. 2005; 58(5):797-800. [PubMed: 16240356] 
7. Weisskopf MG, O'Reilly E, Chen H, Schwarzschild MA, Ascherio A. Plasma urate and risk of Parkinson's disease. Am J Epidemiol. 2007; 166(5):561-7. [PubMed: 17584757]

8. Larumbe Ilundain R, Ferrer Valls JV, Vines Rueda JJ, Guerrero D, Fraile P. Case-control study of markers of oxidative stress and metabolism of blood iron in Parkinson's disease. Rev Esp Salud Publica. 2001; 75(1):43-53. [PubMed: 11400414]

9. Annanmaki T, Muuronen A, Murros K. Low plasma uric acid level in Parkinson's disease. Mov Disord. 2007; 22(8):1133-7. [PubMed: 17443703]

10. Cipriani S, Chen X, Schwarzschild MA. Urate: a novel biomarker of Parkinson's disease risk, diagnosis and prognosis. Biomark Med. 2010; 4(5):701-12. [PubMed: 20945982]

11. Alonso A, Rodriguez LA, Logroscino G, Hernan MA. Gout and risk of Parkinson disease: a prospective study. Neurology. 2007; 69(17):1696-700. [PubMed: 17954784]

12. De Vera M, Rahman MM, Rankin J, Kopec J, Gao X, Choi H. Gout and the risk of Parkinson's disease: a cohort study. Arthritis Rheum. 2008; 59(11):1549-54. [PubMed: 18975349]

13. Lynge E, Sandegaard JL, Rebolj M. The Danish National Patient Register. Scand J Public Health. 2011; 39(7 Suppl):30-3. [PubMed: 21775347]

14. Pedersen CB. The Danish Civil Registration System. Scand J Public Health. 2011; 39(7 Suppl):225. [PubMed: 21775345]

15. Schernhammer E, Hansen J, Rugbjerg K, Wermuth L, Ritz B. Diabetes and the risk of developing Parkinson's disease in denmark. Diabetes Care. 2011; 34(5):1102-8. [PubMed: 21411503] 
Table 1

Association between gout and Parkinson's disease*

\begin{tabular}{|c|c|c|c|}
\hline & Cases $(n=4,484)$ & Controls $(n=22,416)$ & Odds Ratio $(95 \% \text { CI })^{\dagger}$ \\
\hline \multicolumn{4}{|c|}{ Overall } \\
\hline No & 4,299 & 21,537 & 1.0 \\
\hline Yes & 185 & 879 & $1.06(0.90-1.25)$ \\
\hline \multicolumn{4}{|c|}{ Men } \\
\hline No & 2,540 & 12,729 & 1.0 \\
\hline Yes & 136 & 649 & $1.06(0.88-1.28)$ \\
\hline \multicolumn{4}{|c|}{ Women } \\
\hline No & 1,759 & 8,808 & 1.0 \\
\hline Yes & 49 & 230 & $1.07(0.79-1.47)$ \\
\hline \multicolumn{4}{|c|}{ Early Onset ( $<60 \mathrm{y}$ at PD diagnosis) } \\
\hline No & 651 & 3,252 & 1.0 \\
\hline Yes & 15 & 76 & $0.99(0.56-1.73)$ \\
\hline \multicolumn{4}{|c|}{ 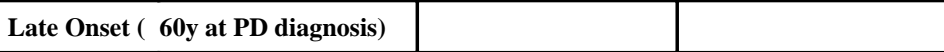 } \\
\hline No & 3,648 & 18,285 & 1.0 \\
\hline Yes & 170 & 803 & $1.07(0.91-1.27)$ \\
\hline
\end{tabular}

Diagnosis of gout based on any prescription of anti-gout drugs (ATC codes M04AA, M04AB, M04AC, M04AX)

adjusting for age, sex, and COPD (lagged 5 years) 